\title{
A sociedade civil organizada e o rompimento da Barragem de Fundão, Mariana (MG): porque é preciso difundir a Geoética
}

ORGANIZED CIVIL SOCIETY AND THE FUndão dAM FAILURE, MARIANA (MG): WHY GEOETHICS NEEDS TO BE MORE DISSEMINATED

Paulo de Tarso A. Castro ${ }^{1}$, Úrsula Ruchrys ${ }^{2}$, Rafael Tertolino Manin $\left.\right|^{3}$

1 - Depto. De Geologia, Escola de Minas, Universidade Federal de Ouro Preto - Campus Morro do Cruzeiro s/N. 35400-000 Ouro Preto. MG.

2 - Depto de Cartografia, Instituto de Geociências, Universidade Federal de Minas Gerals, Av. Antônio Carlos, 6627. 31270-901 Belo Horizonte, MG.

3 - Graduando do Curso de Filosofia - FafiCh, Bolsista de Iniciação Científica do Projeto Geó́tica aplicada à análise do rompimento da Barragem de Fundão e seus efeitos em Bento Rodrigues, Mariana (MG). Universidade Federal de Minas Gerals, Av. Antônio Carlos, 6627. 31270-901 Belo Horizonte, MG.

E-MAILS: PTACASTRO@GMAIL.COM, TULARUCHKYY@YAH00.COM.BR, RAFATERT@HOTMALl.COM

Abstract: Geoethics is an emerging area of geosciences, and the application of its principles is increasingly necessary. The main objective of this article is to analyze the behavior of organized civil society in the face of the consequences of the Fundão Dam failure, in Mariana (MG), considered the greatest environmental catastrophe in Brazil. To do so, this paper presents the relationship between geoethics and mining, and analyzes the reaction by state agencies, NGOs, and the geological scientific and professional community, to the tailings spill from the dam. The analyses indicate the urgent need for a geoethical approach at different levels and in different sectors of the geological community.

\section{Manuscript:}

Received: VIII Simpósio Nacional de Ensino e História de Ciências da Terra / EnsinoGE0-2018. Geociências para Todos

Accepted: 14/01/2018

Citation:Castro P.T.A., Ruchkys U., Manini R.T. 2018. A sociedade civil organizada e o rompimento da Barragem de Fundão, Mariana (MG): porque é preciso difundir a Geoética. Terræ Didatica, 14(4):439-444. URL: http:// www.ige.unicamp.br/terraedidatica/.

Keywords: Geoethics and scientific societies, professional associations, rupture of Fundão dam, geoethics, communication.

\section{Introdução}

Em cinco de novembro de 2015 ocorreu a ruptura de uma barragem de rejeitos de mineração de ferro, pertencente a Samarco Mineração S.A., no município de Mariana, MG. A ruptura da Barragem de Fundão liberou cerca de 32 milhões de $\mathrm{m}^{3}$ de lama de rejeitos que se espalharam ao longo dos cursos de água a jusante da barragem até atingir a foz do Rio Doce, no Espirito Santo. Cerca de 22 milhões de $\mathrm{m}^{3}$ se acumularam nas calhas, encostas $\mathrm{e}$ várzeas do córrego Santarém, rio Gualaxo do Norte e Rio do Carmo, enquanto que cerca de 10 milhões de $\mathrm{m}^{3}$ escoaram pela calha do rio Doce. Dezessete dias após a ruptura da barragem parte desta lama de rejeitos atingiu a foz do Rio Doce.

Este evento causou dezenove mortes e amplos danos socioambientais e comoção da sociedade brasileira. Eventos desta magnitude são muito preocupantes devido à intensidade dos danos ambientais e a extensão de suas consequências para as comunidades locais e das cidades e povoados ribeirinhos, que fazem uso das águas fluviais para consumo e tem atividades pesqueiras ao longo dos cerca de seiscentos e oitenta quilômetros que foram atingidos pelas lamas de rejeito.

Em decorrência do desastre várias entidades se manifestaram, tanto ligadas ao setor governamental como à sociedade civil organizada, envolvendo a proposição de debates, a elaboração de relatórios ou laudos técnicos, dentre outros.

A Sociedade Civil funciona de forma autônoma relativamente ao Estado, organizando-se de forma independente e voluntária. Corresponde à população de cidadãos, ou esfera privada, e abrange suas variadas formas de organização e expressão com ou sem fins lucrativos, podendo ser legalmente constituídas ou espontâneas e informais (Oliveira e Haddad 2001). Na contemporaneidade há uma variação muito grande no uso do termo "sociedade civil organizada" que inclui segmentos diver- 
sos como: associações profissionais, associações científicas, clubes cívicos, cooperativas, grupos ambientalistas, grupos culturais, instituições de benemerência, órgãos de defesa do consumidor, dentre outros. A procura e utilização dos materiais geológicos como fonte de recursos para a humanidade traz consequências impactantes no sistema socioambiental. O caráter difuso, profundo e renitente de tais consequências vem instando na comunidade geocientífica preocupações éticas em relação às práticas da geologia. A geoética surge como resposta a estas preocupações, se ocupando da ética relacionada as consequências sociais, econômicas, ambientais e culturais da pesquisa e da prática geológica (Peppoloni \& Di Capua 2015).

Este texto faz uma análise do comportamento da sociedade civil organizada, em especial do segmento social que tem na geologia a base de suas ações profissionais frente às causas e consequências desta catástrofe, enfocando aspectos relacionados à geoética.

\section{Geoética e Mineração}

A geoética é considerada um campo emergente na área das geociências, sendo que na concepção da Associação Internacional para Promoção da Geoética (IAPG) ela trata das implicações éticas, sociais e culturais da pesquisa e prática geológica, fornecendo um ponto de interseção entre Geociências, Sociologia e Filosofia.

Os conceitos aplicados da geoética podem auxiliar na sensibilização da sociedade aos problemas relacionados ao uso dos recursos geológicos, não renováveis, de forma socialmente e ambientalmente responsável.

A partir da década de 1990 houve um aumento significativo em estudos envolvendo os problemas socioambientais ligados à indústria extrativa mineral incluindo o papel da sociedade, a responsabilidade social das empresas e a geoética (Badera 2014).

Em territórios mineradores do Brasil, como é o caso do Quadrilátero Ferrífero, esses estudos ainda não estão muito desenvolvidos. Dentre os principais problemas estão à expansão das atividades de mineração e uma predominância do modelo reativo em detrimento de uma política de prevenção no que se refere aos impactos dessa atividade. Exemplo disso é o desastre do rompimento da barragem de Fundão que trouxe reação em várias instâncias, a despeito do histórico de rompimento de barragens mostrar que três rompimentos de barragens de rejeito já ocorreram ao longo dos últimos 35 anos.

\section{A Reação do Estado}

Em resposta ao desastre, o Governo de Minas publicou, em 20 de novembro de 2015, o Decreto $\mathrm{n}^{\mathrm{o}} 46.892 / 2015$, que instalou uma Força-Tarefa para avaliação dos efeitos e desdobramentos do rompimento das Barragens de Fundão. Os trabalhos reuniram representantes de órgãos e entidades do Estado e de municípios afetados, e foram coordenados pela Secretaria de Estado de Desenvolvimento Regional de Política Urbana e Gestão Metropolitana, SEDRU (Grupo da Força Tarefa 2016).

O Instituto Brasileiro de Meio Ambiente e dos Recursos Naturais Renováveis, Ibama; o Instituto Chico Mendes de Conservação da Biodiversidade; a Agência Nacional de Águas, ANA; o Departamento Nacional de Produção Mineral, DNPM, representados pela Procuradoria-Geral Federal; o Instituto Estadual de Florestas, IEF, Instituto Mineiro de Gestão de Águas, IGAM, a Fundação Estadual de Meio Ambiente, FEAM, todos representados pela Advocacia-Geral do Estado de Minas; o Instituto Estadual de Meio Ambiente e Recursos Hídricos, IEMA, e a Agência Estadual de Recursos Hídricos, AGERH, todos representados pela Procuradoria-Geral do Estado do Espírito Santo; entraram com ação civil pública contra a SAMARCO em 30 de novembro de 2015.

O Ibama apresentou um laudo técnico preliminar evidenciando os impactos agudos de contexto regional, entendidos como a destruição direta de ecossistemas, prejuízos à fauna, flor e equilíbrio da Bacia Hidrográfica do rio Doce, com desestruturação da resiliência do sistema (Ibama 2015).

O DNPM em nota informativa datada de 14/01/2016 elenca as ações adotadas pelo Órgão após o rompimento da barragem de Fundão: comunicação da ocorrência ao Cenad (Centro Nacional de Gerenciamento de Riscos e Desastres), ANA (Agência Nacional de Águas) e a Secretaria Nacional de Proteção e Defesa Civil, conforme previsto na Lei no 12.334/2010 (Lei da Política Nacional de Segurança de Barragens); realização de inspeção técnica na área no dia seguinte ao rompimento; manutenção de técnicos nas dependências da Samarco para acompanhamento dos trabalhos e comunicação imediata de qualquer anormalidade; monitoramento por meio de inspeções visuais e com utilização de equipamentos das barragens de Santarém, dique da Selinha, dique de Sela, Tulipa e barragem de Germano.

\begin{tabular}{c|c|c|c|c|c}
\hline (c) Terrae Didat. & Campinas, SP & v.14 & n.4 & p. 439-444 & out./dez. 2018 \\
\hline
\end{tabular}


A ANA publicou um encarte especial sobre a Bacia do Rio Doce a partir do rompimento da barragem de Fundão, destacando como principais consequências do evento os impactos na qualidade da água, os quais levaram à interrupção do abastecimento público de algumas cidades e de diversos outros usuários de água. Além disso, outros usos dos recursos hídricos na bacia foram afetados como geração de energia elétrica, indústria, pesca e lazer (ANA 2016).

As promotorias estaduais de Defesa do Patrimônio Cultural e Turístico de Minas Gerais, Promotoria Estadual de Defesa do Meio Ambiente e de Justiça e Meio Ambiente das Bacias dos Rios das Velhas e Paraopeba também tiveram ações exemplares em decorrência do rompimento da barragem.

\section{A Reação da Sociedade Civil Organizada}

\subsection{A reação das Organizações Não Governamentais}

No âmbito da Sociedade Civil Organizada, cabe destaque o relatório elaborado pela Organização Não Governamental (ONG) Justiça Global intitulado Vale de Lama. A Justiça Global foi fundada em 1999 com o propósito de denunciar a violação de direitos humanos. O relatório foi feito em colaboração com várias outras entidades da Sociedade Civil Organizada incluindo: Articulação Internacional dos Atingidos e Atingidas pela Vale; Brigadas Populares; Coletivo Margarida Alves; Comitê Nacional em Defesa dos Territórios frente à Mineração; Conselho Nacional de Direitos Humanos; Movimento dos Atingidos por Barragens - MAB; Movimento Nacional pela Soberania Popular frente à Mineração - MAM; Grupo Política, Economia, Mineração, Ambiente e Sociedade - POEMAS.

O relatório Vale de Lama foi feito dias após o rompimento e denuncia os direitos humanos violados pelo evento: a falta de respostas efetivas por parte do Estado e das empresas; direito à vida, à água, direito à moradia, direito ao trabalho, direito à saúde e o direito a viver em um meio ambiente saudável. Foram colhidos e apresentados os depoimentos de vários moradores de Bento Rodrigues que apontam a negligência da Samarco no tocante a falta de um plano de comunicação e evacuação (Justiça Global 2015).

Da mesma época também é o Relatório apresentado pelo grupo POEMAS: Antes fosse mais leve a carga - avaliação dos aspectos econômicos, políticos e sociais do desastre da Samarco/Vale/BHP em Mariana (MG). O principal objetivo deste relatório foi sistematizar informações sobre o desastre tecnológico da Samarco/Vale/BHP em Mariana, e no rio Doce de forma mais ampla, contribuindo para um debate específico sobre esta questão, como também para colaborar com o aprofundamento da discussão sobre o papel da mineração no Brasil (POEMAS 2015).

A partir da análise são apresentadas várias questões que contribuíram para o desencadeamento do evento tais como: a intensificação da produção de minério de ferro; a precariedade do licenciamento ambiental; a fragilidade do monitoramento de barragens de rejeito; a falta de pessoal e de infraestrutura operacional nos órgãos de controle ambiental que muitas vezes não tem independência política; dentre outras.

\subsection{A reação da comunidade científica geológica.}

Foram analisadas duas entidades ligadas a geologia de engenharia: Associação Brasileira de Mecânica dos Solos e de Engenharia Geotécnica (ABMS), Associação Brasileira de Geologia de Engenharia e Ambiental (ABGE), e duas entidades ligadas a aspectos gerais das geociências: Sociedade Brasileira de Geologia (SBG) e Sociedade Brasileira de Ciência do Solo (SBCS).

As primeiras semanas foram concentradas em assistir às comunidades atingidas pelas lamas de rejeito em consonância com a comoção nacional e a mobilização da população.

Imediatamente após a ruptura da barragem, dois pontos chamaram a atenção da comunidade científica e profissional da geologia: as causas da ruptura da barragem de rejeitos e a situação de estabilidade das barragens instaladas nas regiões montanhosas de Minas Gerais, que as concentra em expressivo número.

Nessa seara atuam as duas primeiras entidades analisadas. A ABMS é uma associação técnico-científica fundada em 1950, congrega os profissionais geotécnicos que atuam em Mecânica dos Solos, Mecânica de Rochas, Mecânica dos Pavimentos, Fundações, Barragens, Escavações, Túneis, Mineração, Geossintéticos, Geotecnia Ambiental, Aterros Sanitários, Geomecânica do Petróleo, e demais atividades da Engenharia Geotécnica (www.abms.com.br).

Dois especialistas do ABMS foram ouvidos por uma longa reportagem apresentada no Programa

\begin{tabular}{l|l}
\hline (C) Terrae Didat. & Campinas, SP \\
\hline
\end{tabular} 
Fantástico na edição do dia 15 de novembro de 2015: Alberto Sayão, ex-presidente da entidade e professor da PUC-Rio, e Romero Gomes, professor da Universidade Federal de Ouro Preto. Os especialistas discorreram sobre os aspectos geotécnicos associados ao rompimento da barragem.

Em 27 de novembro do 2015, a ABMS se manifestou propondo a criação de uma comissão técnica de alto nível para promover uma investigação profunda sobre as causas da ruptura da barragem. Em seu editorial desta data a entidade coloca: "Desde o último dia 5 de novembro estamos assistindo a cenas muito tristes para a sociedade brasileira em geral, que vão desde a lamentável perda de vidas humanas, a destruição devastadora de povoados e de seus patrimônios histórico, cultural e social, os impactos ambientais de grande monta em valor e extensão, a interrupção de abastecimento de água de cidades importantes ao longo do vale do Rio Doce e incalculáveis prejuízos diretos e indiretos. Tudo isso decorrente da ruptura da barragem do Fundão, pertencente ao complexo da mineradora Samarco, uma barragem de rejeitos".

A Diretoria da ABMS ainda coloca que é preciso reconhecer que se houve uma falha é necessário melhorar nossos padrões de engenharia: "É preciso aprender com os acidentes e transformá-los em lições".

A ABGE realizou uma mesa redonda especificamente sobre o rompimento da Barragem de Fundão e gestão de segurança e risco de barragens de mineração no III Congresso da Sociedade de Análise de Risco Latino Americana, realizado em São Paulo, em 2016.

A SBG foi criada em 1945 e tem como missão "fomentar o conhecimento e o desenvolvimento das geociências, da geologia aplicada e da pesquisa e tecnologia correlata e o aproveitamento racional e sustentável de recursos minerais e hídricos". Um dos objetivos da Sociedade colocados em seu site de divulgação é "defender a utilização dos recursos minerais e hídricos segundo os princípios do desenvolvimento sustentável". Castro (2016a e 2016b 2017) destaca que apesar do rompimento da barragem de Fundão ter ocorrido devido à intervenção humana em sistemas naturais a SBG não se pronunciou oficialmente. A sociedade também não se pronunciou sobre dois pontos de preocupações gerais: as causas da ruptura e a situação de estabilidade das barragens de rejeitos de mineração. $\mathrm{Na}$ ocasião do seu Congresso Nacional, no ano de 2016, embora tenha sido instada por associados a estabelecer fóruns de debates sobre o ocorrido, a diretoria nacional não se pronunciou a respeito. Limitou-se a realizar uma mesa redonda sobre estabilidade de barragens.

A Sociedade Brasileira de Ciência do Solo (SBCS) publicou um boletim especial sobre os depósitos de lama nas várzeas e encostas dos rios atingidos e perspectivas de recuperação da vegetação (SBCS 2016)

\subsection{A reação das entidades profissionais em geologia.}

O Sindicato dos Geólogos no Estado de Minas Gerais (Singeo) emitiu opinião em seu órgão oficial de comunicação trimestral, o Jornal Martelando, nas edições do último trimestre de 2015 (Singeo 2015) e primeiro trimestre de 2016 (Singeo 2016). No primeiro (Singeo 2015) o sindicato assina uma matéria em que expõe preocupações quanto à efetividade das fiscalizações da FEAM e do DNPM e da legislação em vigor. Também traz análises sobre o rompimento de da Barragem de Fundão por geólogos. No segundo (Singeo 2016) traz opiniões de geólogos expressas em outras fontes com análises a respeito do rompimento da barragem. Nos números seguintes de 2016 e ao longo de 2017 o assunto foi sendo esquecido

A Federação Brasileira de Geólogos (Febrageo), representada pelo seu presidente participou da reunião da Comissão de Infraestrutura do Senado Federal onde expôs a dimensão da catástrofe e a pouca eficácia dos órgãos de controle ambiental e da mineração. Atuou junto ao Sistema Confea/ Creas na tomada de posição a respeito da ruptura da Barragem de Fundão e seus danos ao ambiente

\subsection{A reação dos órgãos regulamentadores da profissão.}

O Crea-MG, Conselho Regional de Engenharia e Agrimensura em Minas Gerais, órgão que regulamenta a atividade profissional dos geólogos e engenheiros geólogos realizou workshop sobre riscos naturais relacionadas às obras de engenharia de grande porte. No entanto, apesar de o Código de Ética do Engenheiro indicar a sociedade como o fim a que se propõe a atuação profissional do engenheiro o workshop se concentrou nos processos naturais como causas de riscos e grandes obras.

\begin{tabular}{c|c|c|c|c|c}
\hline C Terrae Didat. & Campinas, SP & v.14 & n.4 & p. 439-444 & out./dez. 2018 \\
\hline \multicolumn{2}{|c|}{442}
\end{tabular}




\section{Conclusão}

Embora os aspectos técnicos que levaram ao rompimento, ou que sirvam de base para ações de restauração ambiental tenham sido tratados pelas entidades aqui analisadas, o mesmo não pode ser dito em relação as consequências socioambientais da liberação de lama de rejeito ao longo dos rios atingidos que recebeu pouca ou quase nenhuma atenção.

No contexto da catástrofe que atingiu a bacia do Rio Doce, ao serem confrontadas as reações dos órgãos governamentais, da sociedade civil, das associações científicas e técnicas e das reguladoras profissionais, alguns pontos devem ser salientados e que devem fazer parte das discussões das sociedades científicas e profissionais, realizadas a partir do aumento da difusão da geoética entre os cientistas, docentes, discentes e profissionais da área no Brasil. Alguns deles são abaixo enunciados e comentados:

- Processos de restauração fluvial e dos serviços ambientais nos rios, córregos e várzeas. Embora seja da competência do geólogo as intervenções em sistemas fluviais em função de seus conhecimentos em geomorfologia, sedimentologia, mineração e impactos ambientais, pouco tem se trabalhado nos cursos de graduação sobre este tema. A ligação com os valores e modos de produção das comunidades locais em diferentes escalas pode ser importante para a sociedade;

- O que fazer com os rejeitos acumulados ao longo dos rios Gualaxo do Norte, A solução implementada e decidida a priori pela empresa responsável pela catástrofe e por suas controladoras foi a de não retirar a lama de rejeito depositada nas calhas, várzeas e encostas dos sistemas fluviais atingidos. As exceções a este procedimento concentraram-se nas cidades, vilas e povoados atingidos pelas lamas de rejeito e no lago da Usina Hidrelétrica de Candonga, cuja operação ficou inviabilizada pelo acúmulo de lama no reservatório. Ou seja, onde houve danos reais e diretos à população, com o entulhamento de casas, arruamentos e onde houve cessação de lucros de empreendimentos de porte significativo, optou-se pela retirada da lama. Não foram levadas em consideração as experiências exitosas realizadas em situações semelhantes às acontecidas, de retirada de lamas de rejeitos de minas em canais, várzeas e encostas de rios, na Espanha, em 1998 (Antón-Pacheco et al. 2001). Ao se analisar as propostas contidas na publicação SBCS (2016), pode-se perceber que são propostas metodológicas de ação, sem respaldo em procedimentos em situações similares.

- o geólogo e a catástrofe da Samarco: lições a serem aprendidas. Como pode ser verificado acima, pouco se deu atenção às consequências socioambientais da catástrofe da ruptura da Barragem de Fundão. As sociedades científicas e profissionais não se pronunciaram sobre o assunto, com a veemência necessária. Há uma prevalência, ainda que velada nos meios científicos, das preocupações relativas à profissão e ao profissional e ao emprego em detrimento dos danos socioambientais do extravasamento da lama de rejeito e sua dispersão pela bacia do Rio Doce.

- O papel das associações científicas, seus congressos e simpósios e a sustentabilidade das regiões em que a mineração seja uma importante indústria. Os preceitos da geoética devem ser incorporados como pauta específica e ao mesmo difusa, permeando as temáticas dos encontros científicos, incorporando valores e estabelecendo posicionamentos.

- Os cursos de geologia e engenharia geológica e a catástrofe da Samarco. À semelhança do que vem acontecendo com as questões ambientais ao longo das quatro últimas décadas, devem ser implantados os princípios da Geoética nos cursos de graduação, ressaltando as incongruências entre a finitude dos recursos naturais, o avanço tecnológico e o ainda descontrolado crescimento populacional humano e as práticas tecnicistas despojadas da responsabilidade para com a sociedade e para com o Planeta.

Acredita-se que a Geoética, enquanto preocupada com o papel e responsabilidade social dos geólogos no desenvolvimento de suas atividades pode ser um ponto de apoio fundamental na tomada de consciência social da profissão. Nas atividades de mineração, sobretudo aquelas que extraem materiais geológicos e os utiliza como recursos para uma sociedade globalizada e, portanto, nem sempre aproveitáveis pelas comunidades locais, há uma grande dicotomia de valores: valores monetários diretos e precificados globalmente, como commodities e valores locais, dificilmente quantificáveis, 
como são a utilização dos sistemas ambientais em baixa e média escalas pelas populações potencialmente atingidas, como a pesca, a irrigação de várzeas, dessedentação de animais e consumo humano.

Os efeitos da dispersão da lama de rejeito liberado pelo rompimento da Barragem de Fundão nos dão uma visão de como a sociedade civil organizada, em especial aquelas organizações voltadas ao ensino, pesquisa e profissão em geologia estão alheias aos princípios geoéticos de norteamento das relações entre a ciência geológica, suas técnicas e a sociedade.

\section{Agradecimentos}

Os autores agradecem ao CNPq pela concessão da bolsa de iniciação cientifica no Edital PIBIC/PROBIC-UFMG -05/2017 referente ao Projeto Geoética aplicada à análise do rompimento da Barragem de Fundão e seus efeitos em Bento Rodrigues, Mariana (MG).

\section{Referências}

ANA. Agência Nacional das Águas. 2016. Encarte especial sobre a Bacia do Rio Doce. Rompimento da barragem em Mariana/MG. Brasília. Super. Planej. Rec. Hídricos. 50p.

Antón-Pacheco C., Arranz J.C., Barettino D., Carrero G., Giménez M., Gómez J.A., Gumiel J.C., López Pamo E., Martín Rubí J.A., Martínez Pledel B., de Miguel E., Moreno J., Ortiz G., Rejas J.G., Silgado A., Vázquez E.M. 2001. Actuaciones para el reconocimiento y retirada de los lodos depositados sobre el terreno, y su restauración edáfica y morfológica. Boletín Geológico y Minero, Vol. Esp.: 93-122.

Badera J. 2014. Problems of the social non-acceptance of mining projects with particular emphasis on the European Union. A literature review. Environmental \& Socio-economic Studies, 2(1):27-34.

Castro P.T.A. 2016a. A tragédia Samarco em Mariana
(MG) e seus efeitos ao longo do Rio Doce: porque é preciso difundir a geoética In: Congr. Bras. Geol., 48, Porto Alegre, 2016. Resumos... Porto Alegre, SBGeo.

Castro P.T.A. 2016b. Geoética. In: Mort H., Stewart I., Frank H.T., Castro P.T.A., Poester O. 2016. Mesa Redonda sobre Geoética e Geocomunicação. In: Congr. Bras. Geol., 48, Porto Alegre, 2016.

Castro P.T.A. 2017. Geoética. In: Mesa Redonda sobre Geoética. 39 Encontro Nacional dos Estudantes de Geologia, 2017, Ipoema.

Grupo da Força Tarefa. 2016. Avaliação dos efeitos e desdobramentos do rompimento da Barragem de Fundão em Mariana, MG. Belo Horizonte, Secr. Est. Desenv. Reg., Polít. Urbana e Gestão Metropolitana, Gov. Minas Gerais. 287p.

Ibama. Instituto Brasileiro do Meio Ambiente e dos Recursos Naturais Renováveis. 2015. Laudo técnico preliminar: impactos ambientais decorrentes do desastre envolvendo o rompimento da barragem de Fundão, em Mariana, MG. 38p.

Justiça Global. 2015. Vale de Lama. Relatório de inspeção em Mariana após o rompimento da barragem de rejeitos do Fundão. 44p.

Oliveira A.C., Haddad S. 2001. As organizações da sociedade civil e as ONGS de educação. Cadernos de Pesquisa, n.112, p. 61-83.

Poemas. Grupo Política, Economia, Mineração, Ambiente e Sociedade. 2015. Antes fosse mais leve a carga: avaliação dos aspectos econômicos, políticos e sociais do desastre da Samarco/Vale/BHP em Mariana (MG). Mimeo. 103 p.

Peppoloni S., Di Capua G. 2015. The meaning of geoethics. In: Wyss M., Peppoloni S. 2015. Geoethics. Ethical Challenges and Case Studies in Earth Sciences. Amsterdam: Elsevier. p. 3-14.

SBCS. Sociedade Brasileira de Ciência do Solo. 2016. A ciência do solo e o desastre de Mariana. Bol. Informativo, 42(1).

Singeo. Sindicato dos Geólogos no Estado de Minas Gerais. 2015. Jornal Martelando. Informativo Oficial do Sindicato dos Geólogos no Estado de Minas Gerais, (26).

Singeo. Sindicato dos Geólogos no Estado de Minas Gerais. 2016. Jornal Martelando. Informativo Oficial do Sindicato dos Geólogos no Estado de Minas Gerais, (27). 